\title{
Inclusion/Melt Compatibility in Pure Nickel and UDIMET 720
}

\author{
M.Halali, D.R.F.West and M.McLean \\ Department of Materials, Imperial College of Science, Technology and Medicine, \\ Prince Consort Road, London SW7 2BP, UK
}

\begin{abstract}
The inclusion content and distribution in the alloy UDIMET 720 has been studied using levitation melting. Samples of the as-cast alloy have been melted and the inclusions that concentrate on the surface have been characterised. The specific behaviour of some typical inclusions such as $\mathrm{Al}_{2} \mathrm{O}_{3}$, TiN, and the spinel $\mathrm{Al}_{2} \mathrm{MgO}_{4}$ has been studied by deliberately adding particles onto the surface of the molten levitated sample. Light microscopy and SEM together with EDS analysis have been employed to study the surface and sections of the solidified samples. Most of the inclusions display "nonwetting" behaviour; the few "wetting" inclusions were complex oxides of aluminium, titanium, silicon, and calcium. It is found that most of the wetting complex oxide inclusions are associated with sulphur. Other wetting inclusions identified (TiN, chlorides and fluorides of alkali metals and calcium) are generally secondary inclusions that form on solidification. Although sulphur is associated with most of the wetting complex oxide inclusions, the addition of $15 \mathrm{ppm}$ sulphur does not significantly change the wetting characteristics of the non-wetting inclusions.
\end{abstract}

\section{INTRODUCTION}

As turbine disc alloys have developed with increasing yield strengths to satisfy the requirement for increasing stresses associated with reduced engine weight and increased rotor speeds, there has been a concomitant increase in the sensitivity of these materials to fracture at defects such as inclusions. This has led to a demand for improved cleanness (or decreased inclusion content) using a range of primary and secondary melting procedures such as VIM, VAR, ESR, and EBCHR. Detection of these sparse inclusions is beyond the scope of current NDE and quality assurance and is likely to be achieved through control of the alloy processing.

In studying the intrinsic interactions between inclusions and the melt, it is importaut that the system is not distorted by the presence of ceramic crucibles. A few cold crucible and containerless procedures, including electron beam button melting and magnetic suspension (levitation) melting ${ }^{(1-12)}$, have been used to avoid this problem and for fundamental studies. Most of these modern techniques for inclusion investigation and removal rely on the fact that many inclusions, particularly those with larger sizes (e.g. 100 $\mu \mathrm{m})$ tend to be retained on the surface of the molten alloys. There Superalloys 1996

Edited by R. D. Kissinger, D. J. Deye, D. L. Anton

A. D. Cetel, M. V. Nathal, T. M. Pollock, and D. A. Woodford

The Minerals, Metals \& Materials Society, 1996 is debate as to whether this phenomenon is due primarily to flotation or to the effect of surface tension. Levitation melting ${ }^{(3)}$ was used in the present study to characterise the wetting behaviour of inclusions in the molten nickel-base alloy UDIMET 720. The inclusions studied include those found in the as-supplied alloy, both primary inclusions present in the melt and secondary inclusions which form on solidification due to falling solubility limits. A good example of the first is alumina which can be present in the source metals or can be debris from the crucible linings during alloy production. TiN is an example of secondary type inclusions which are generally very small. The size of the primary inclusions can vary over a wide range; alumina particles larger than $100 \mu \mathrm{m}$ can be found. Typically TiN particles are $\approx 1 \mu \mathrm{m}$ diameter although these may congregate in clusters. A better understanding of the physicochemical relationships between the superalloy and the inclusions is required to develop reliable clean processing procedures.

\section{EXPERIMENTAL DETAILS}

Levitation experiments were carried out on both UDIMET 720 and pure nickel using the apparatus shown schematically in Figure 1. Power was supplied by a $15 \mathrm{~kW}, 450 \mathrm{kHz}$ Radyne generator and an inert atmosphere was maintained inside silica tubes $14 \mathrm{~mm}$ OD. In most experiments helium was used to give additional control over the temperature of the molten sample by virtue of its high thermal conductivity; otherwise argon was used. Nickel samples were cut from specpure nickel rods and alloy samples from a cast UDIMET 720 ingot supplied by Rolls Royce.

The levitation coil was made from copper tubing $3 / 16^{\prime \prime} \mathrm{OD}$ and $0.030^{\prime \prime}$ wall thickness. Of 30 coil geometries considered, that shown in Figure 1 gave stable drops with the optimum combination of melt size and temperature. Temperature could be measured by a disappearing filament pyrometer from the bottom prism, top window and mirror, or directly from the sample. The first two methods were most convenient but had an uncer lainty of $\approx 30^{\circ} \mathrm{C}$, so the third was used when possible because of improved accuracy.

Prior to every experiment surfaces were (i) ground with silicon carbide paper, (ii) ultrasonically cleaned in a dilute solution of "Decon $90^{\prime \prime}$ at $60^{\circ} \mathrm{C}$ for $10-15$ minutes, (iii) washed sequentially in water, distilled water and acetone, (iv) dried and (v) stored in a desiccator. Each silica tube was washed in a hot solution of dilute 


\begin{tabular}{|c|c|c|c|c|c|c|c|c|c|c|c|}
\hline & 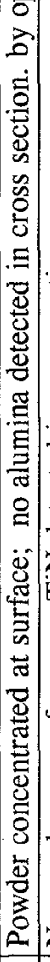 & : & & 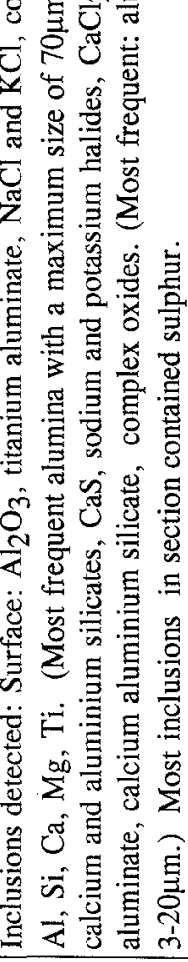 & 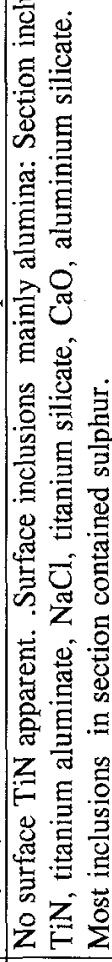 & 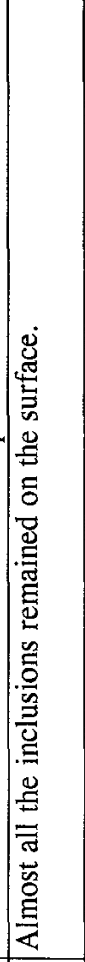 & 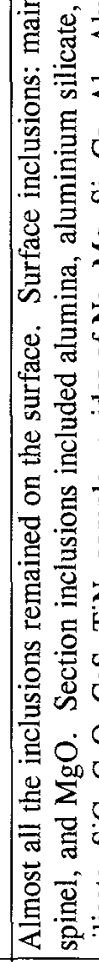 & 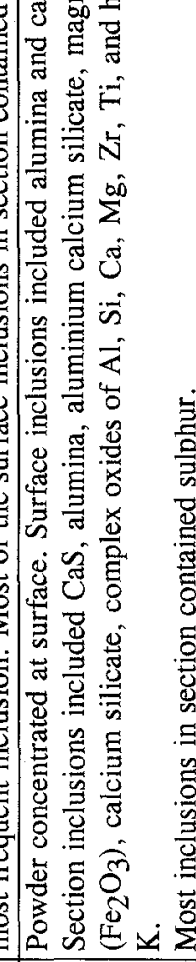 & 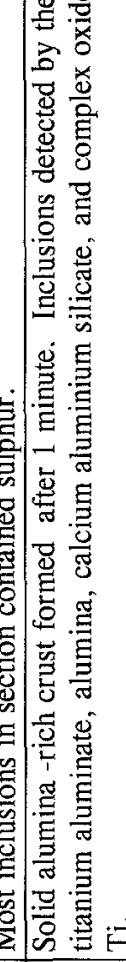 & 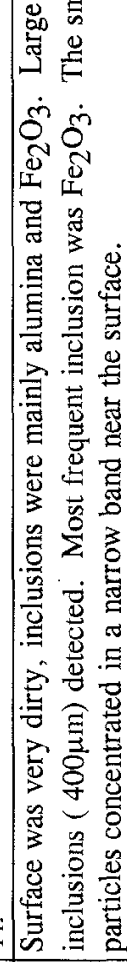 & 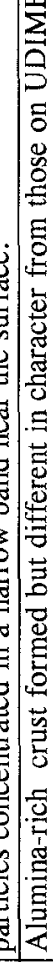 \\
\hline 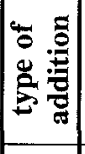 & 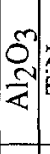 & & & & $Z_{i}$ & $\delta^{\prime}$ & 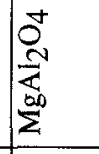 & $\mathscr{J}$ & $\vec{U}$ & & 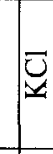 \\
\hline 氞 & $\sim$ & $\begin{array}{l}4 \\
\end{array}$ & & $m$ & in & - & $\sim$ & $m$ & | & 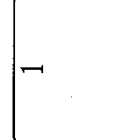 & $\cong$ \\
\hline 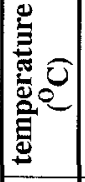 & 号 & 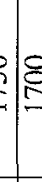 & & $\stackrel{9}{\stackrel{9}{ \pm}}$ & 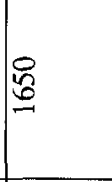 & 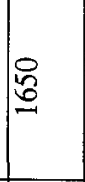 & 号 & 㣟 & 约 & $\underset{\wedge}{\stackrel{8}{\Lambda}}$ & 煦 \\
\hline 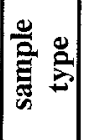 & $\ddot{z} \mid$ & 2 & & 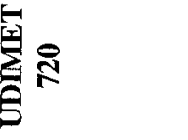 & 通 & $\sum_{5}^{5}$ & 氛 & 箅 & 䌿 & 点施 & $\begin{array}{l}z \\
8 \\
0 \\
z \\
z\end{array}$ \\
\hline
\end{tabular}


nitric acid, rinsed, and dried before each run. In some runs, where the sample was quenched in a copper cup, the copper cup was cleancd in dilute nitric acid, rinsed with distilled water and dried.

The sample and the copper cup (when used) were weighed separately. These and the powder were then placed on boron nitride trays in separate compartments of the turntable which was raised to the level of the coil using an alumina tube. The chamber was flushed with inert gas for 5 minutes, the gas flow rate was set and the generator turned on. Time was measured from complete melting of the sample which usually took 20 to 50 seconds depending on power, gas flow rate, and the weight of the sample. Various fine ceramic powders could be introduced to the molten levitated drop by bringing the sample holder close to the drop (Figure 1, inset) and allowing the gas stream to blow the powder onto the surface of the drop.

Some samples were quenched in the copper cups; the rest were solidified in situ which was achieved by suddenly increasing the power setting of the induction generator which disturbed the levitation conditions removing the drop from the hot zone and simultaneously increasing the gas flow rate (to $\approx 30 \mathrm{litres} / \mathrm{min}$ ). In situ solidification took 5 to 10 seconds. After cooling, the samples and copper cups were weighed. The surfaces were examined by SEM. prior to sectioning, using thin silicon carbide slitting wheels $\left(0.010^{\prime \prime}\right.$ thick). They were then ground and polished to $1 \mu \mathrm{m}$ using diamond compounds. Each solidified drop was systematically investigated by optical microscopy, SEM with EDS analysis and Xray diffraction to determine the nature of inclusions and their distribution across the section.

\section{RESULTS AND DISCUSSION}

A summary of the observations made on specimens subjected to various levitation melting conditions are summarised in Table 1. Figures 2 and 3 show photographs of selected samples which have been solidified in situ. Where surface inclusions are evident they are concentrated in a circumferential band consistent with the intersection of convective flow patterns with the surface as proposed by Marechal et al. ${ }^{(3)}$. Several series of levitation experiments on pure nickel and UDIMET 720 with various deliberate additions of particles have been undertaken and the inclusion distribution characterised. The criterion for non-wetting of inclusions was the retention of the powder on the surface. However, it is possible to have particles that both remain on the surface and are entrained in the metal. This is discussed below.

\section{Levitation melting of pure nickel.}

Since nickel is the chief constituent of UDIMET 720 , reference cxperiments were made using pure nickel. When nickel was levitated on its own inclusions neither concentrated on the surface nor were apparent in the cross-section consistent with the high purity of the starting material. This indicates that the experimental procedure does not introduce extraneous imclusions.

Three different types of powder - alumina, TiN, and the $\mathrm{Al}_{2} \mathrm{MgO}_{4}$ spinel -were added to pure nickel in separate levitation runs. The particle sizes used were as follows: two types of alumina were used in separate experiments with particle sizes in the approximate ranges of $50-200 \mu \mathrm{m}$ and $<10 \mu \mathrm{m}$; the spinel was $30-100 \mu \mathrm{m}$ and the TiN was predominantly $<1 \mu \mathrm{m}$ with a some particles up to $5 \mu \mathrm{m}$ :
- Alumina was added to levitated samples at several different temperatures between $1500^{\circ}$ and $1800^{\circ} \mathrm{C}$ : the durations of the runs varied from 10 seconds to 12 minutes. Most of the alumina, which was in the form of particles of $\approx 30( \pm 10) \mu \mathrm{m}$ diameter, remained on the surface with no discernible change in size or morphology. No alumina particles could be identified by SEM of the sectioned samples in agreement with Ellis.

- When the spinel, of similar particle size to the alumina, was added the particles also remained on the surface. This behaviour differs from that reported by Ellis. There are important differences in the two studies; the source of spinel particles and the methods of introducing powders to the sample. Ellis introduced the powder into a hole bored in the solid sample before levitation; this allows very precise gravimetric studies but there is the inherent risk of particle agglomeration and sudden powder loss. Also, Ellis used a maximum melt duration of 1 minute measured from the point of levitation; in the present study, the sample was levitated for 2 minutes measured from complete melting.

- When titanium nitride was added, this time in the form of a very fine powder with a mean particle size of $\approx 2 \mu \mathrm{m}$, the particles disappeared from the surface. Also, few titanium nitride particles were detected in the sectioned sample. It is likely that most of the powder dissolved in the metal rather than being retained as TiN

\section{Levitation melting of UDIMET 720}

The as-supplied alloy was studied by SEM before and after levitation to identify as many types of inclusions as possible. The inclusions detected by SEM on the surface were assumed to be non-wetting; those found in the sections of samples were assumed to be wetting. The temperature of the levitated melts varied between 1585 and $1750^{\circ} \mathrm{C}$ and the duration of the runs between 5 seconds to 7 minutes. The temperature and duration of runs did not have a significant effect on the inclusion distribution.

a) Surface inclusions: Alumina was the most frequent type of surface inclusion observed occurring in a range of sizes from a few to $150 \mu \mathrm{m}$. Other inclusions detected were titanium aluminate and complex oxides of aluminium, silicon, calcium, magnesium, and titanium. Halides of reactive metals were occasionally identified.

The alumina particles detected could have been intrinsic to the alloy originating from oxidation reactions and agglomeration to form large inclusions. They may also be extrinsic debris from the ceramics and refractories used in melting. The complex oxides are deduced to be agglomerates of simpler compounds such as oxides and spinels that are most likely to be picked up from refractory linings during melting. The origin of the halide particles is not clear. Most manufacturers use a proportion of scrap in alloy production; if part was from ESR material, halide contamination trom the slag may have persisted. It unlikely that the halides would be stable in the melt; more likely they precipitate as secondary inclusions. 


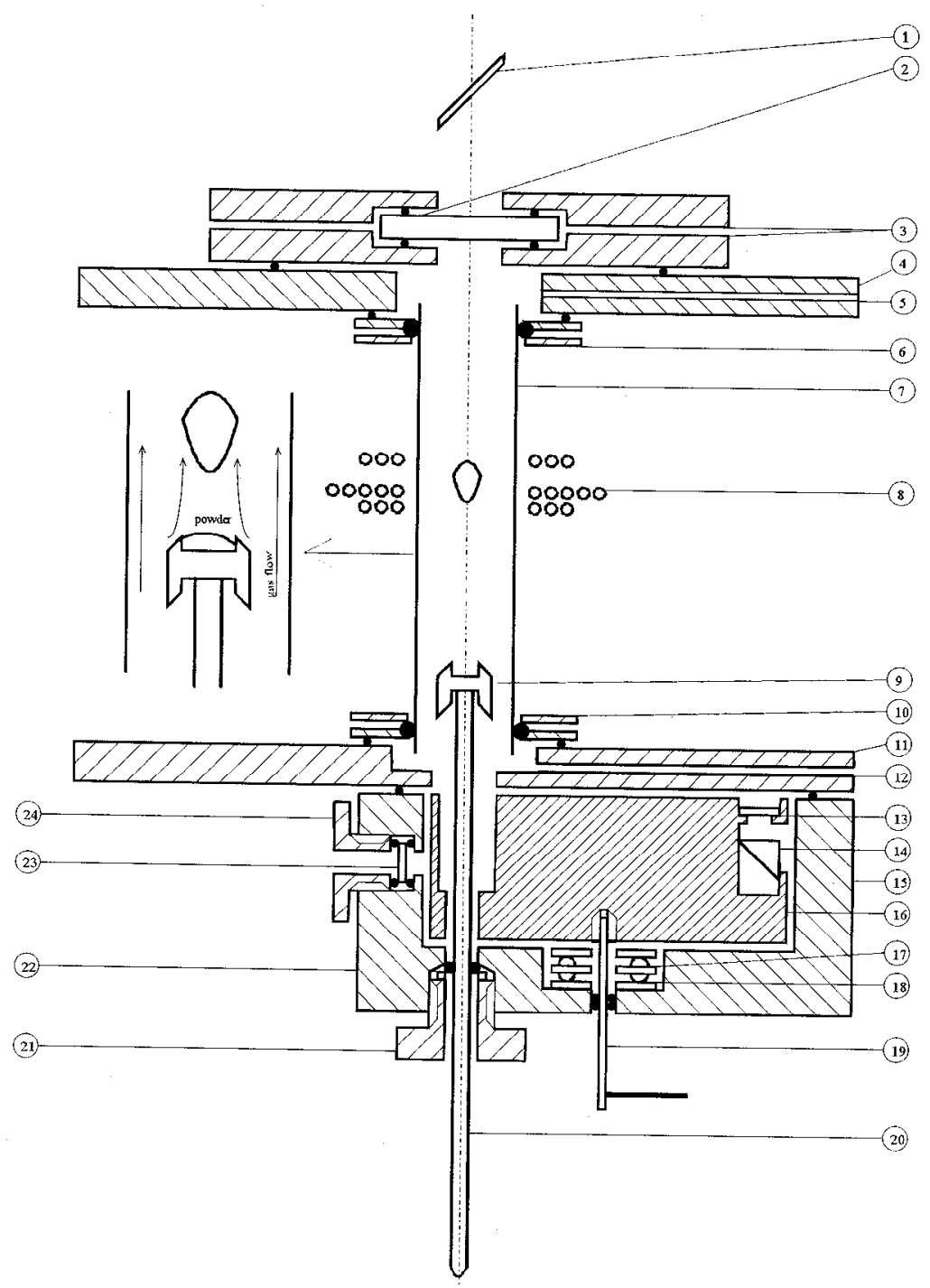

1) mirror

2) top optical window sealing plates

13) prism optical window

3) top optical window

14) prism

4) gas outlet

5) top flange

15) turn table case

16) turn table

6) top sealing arrangement

17) ball bearing

7) silica tube

18) ball bearing washers

8) levitation coil

19) turn table handle

20) alumina push rod

9) sample holder

10) bottom sealing arrangement

21) alumina push rod sealing gland

11) bottom flange

22) alumina push rod washer

23) bottom optical window

12) gas inlet

24) bottom optical window sealing gland

Figure 1: Schematic diagram of the levitation chamber. (not to scale) 


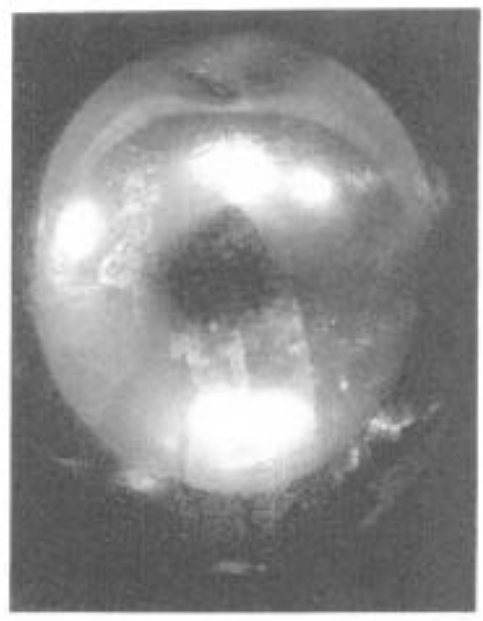

a

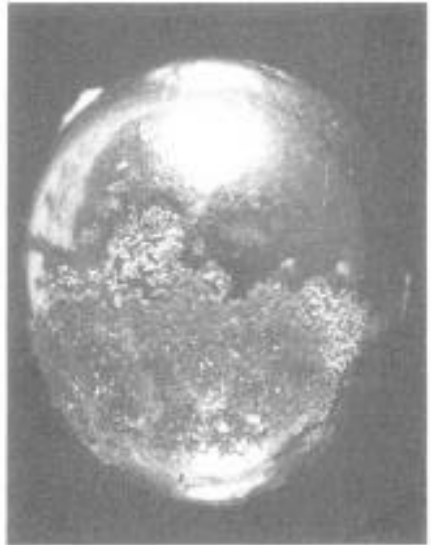

b

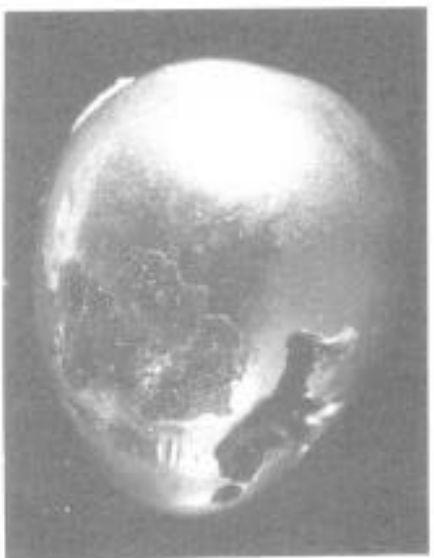

c

Figure 2: $\quad$ Samples of pure nickel after levitation melting:

(a) pure nickel, (b) pure nickel with $\mathrm{Al}_{2} \mathrm{O}_{3}$ and (c) pure nickel with $\mathrm{Al}_{2} \mathrm{O}_{3}$ and $\mathrm{KCl}$ additions.

Scale:

b) Section inclusions: Although a large proportion of inclusions came to the surface, some particles remained inside the samples. The inclusions detected in the section were generally smaller than those on the surface and there was a wider variety of inclusion types in the section. The most frequently occurring inclusions were different compositions of aluminium silicate with sizes between 3 and $20 \mu \mathrm{m}$. Other inclusions detected were alumina. TiN, calcium silicate, aluminium silicate, CaS, halides of reactive metals, and complex oxides of aluminium, silicon, calcium, titanium and magnesium. Most inclusions within the sections contained sulphur.

One expcriment was carried out on material cut from the inclusionrich cap produced during electron beam button melting. After levitation melting the surface of the drop had a much higher coverage by particles than was obtained from the ingot alloy indicating a high cleaning efficiency during levitation melting.

\section{Addition of inclusions to UDIMET 720}

Since it was not possible to isolate specific chemistries of the complex oxides found in the commercial alloy, deliberate additions were made of a range of relatively simple compounds, including alumina, spinel, silica, lime, magnesia and titanium nitride.

- When the oxide particles were added to a levitated sample, all the particles seemed to remain on the surface of the sample; different temperatures and durations of levitation did not change the behaviour significantly. Metallographic examination of the surfaces and sections of solidified samples confirmed the visual observation during levitation melting.
- On addition of TiN, all of the powder apparently disappeared. A very few TiN particles were detected on the sectioned drops. Titanium has a high solid solubility in nickel $(7$ at. \%). Nitrogen, on the other hand, is quite insoluble in nickel. It is possible that the particles have dissolved in the alloy, titanium being retained in solution.

\section{Addition of surface active compounds to UDIMET 720}

During levitation melting induced electrical currents at the surface generate vigorous eddy currents which carry inclusions to the surface and then return a proportion of them to the bulk If an addition can be made which would retain the inclusions on the surface, the bulk of the sample will have a reduced inclusion content. The ideal addition would both modify the surface characteristics of the melt and inclusion to enhance their nonwettability and would fuse the inclusions retained on the surface. Halides of reactive metals appear to have both of these properties.

In several experiments salts such as $\mathrm{NaCl}, \mathrm{KCl}, \mathrm{KF}, \mathrm{CaF}_{2}$, and $\mathrm{CaCl}_{2}$ were added to levitated samples. After a period of between few seconds to just over a minute, a solid crust formed on the molten samples. The time taken for the crust to form depended on the chemistry and concentration of the salt. Salts of the more reactive elements such as KF took only a few seconds to form the crust; maintaining the sample in the state of levitation resulted in wrinkling of the crust and elongation of the sample. The formation of the crust reduced the convection currents and cooling rates making in situ solidification impracticable. Solidification was achieved by quenching in a cold copper crucible. Metallographic 

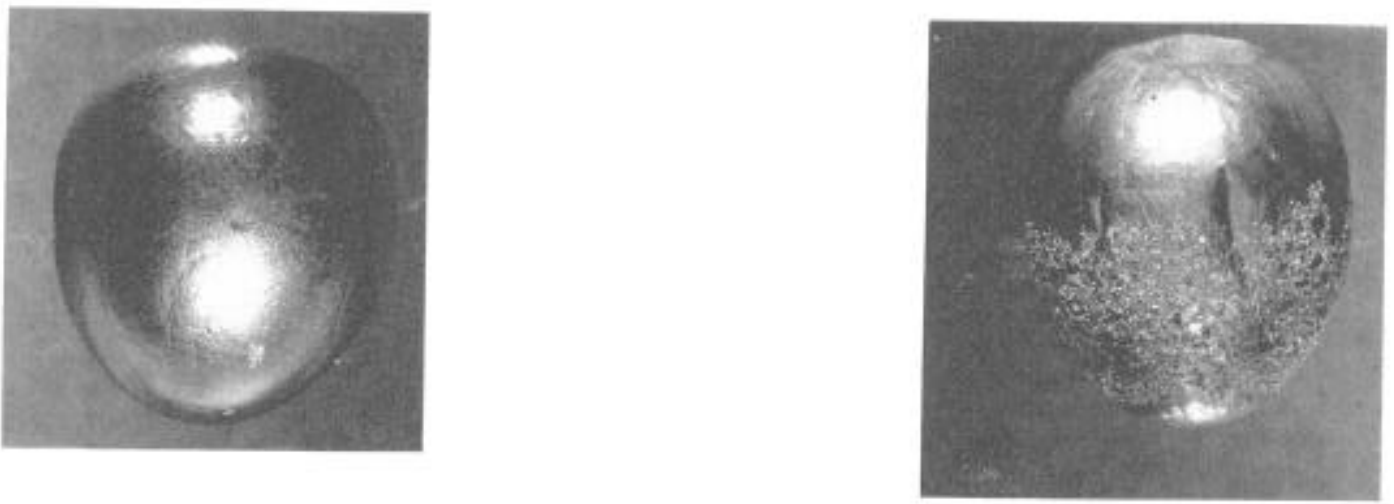

a

b

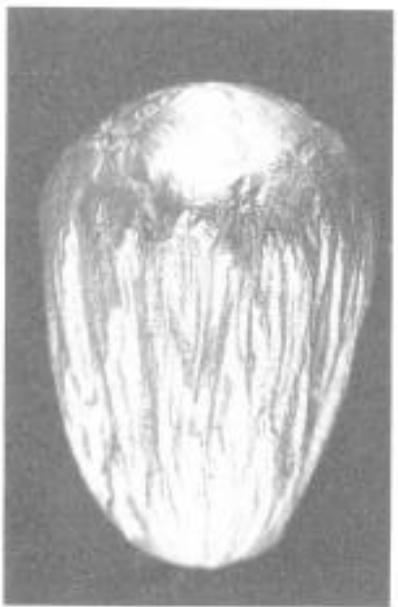

c

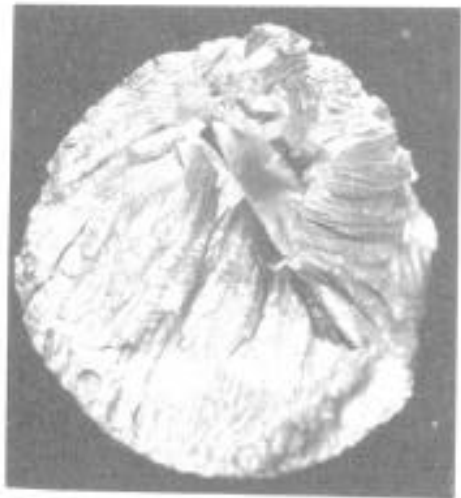

d

Figure 3 Samples of UDIMET $\mathbf{7 2 0}$ after levitation melting:

(a) as-supplied, (b) with alumina addition, (c) with $\mathrm{Al}_{2} \mathrm{O}_{3}$ and $\mathrm{KCl}$ additions and (d) $\mathrm{Ni}-3 \%$ A $\mathrm{c}$ addition.

Scale

$5 \mathrm{~mm}$

examination of the sections showed them to be considerably cleaner than those without surface active additions. Figure 4 shows parts of sections of the UDIMET 720 alloy samples in different conditions: as-supplied, levitated on its own, and levitated with the addition of $\mathrm{KCl}$. It is quite evident that the sample with the halide addition bas many fewer internal inclusions than the other two samples.

$\mathrm{X}$-ray diffraction showed the crust to consist mainly of alumina. The formation of the crust could result from various effects. One possible mechanism, by oxidation of aluminium in the alloy by the residual oxygen in the cooling gas which is at a level of a few ppm. can be ruled out since the crust does not form in the absence of the reactive additions.
No crust was observed when halides were added to levitated samples of pure nickel. Levitated pure nickel samples were sprayed by a mixture of alumina and halides and still no scale was formed. Thus the formation of the crust must be related to the presence of the inclusion particles and/or the aluminium content of the alloy.

When samples of an alloy of $\mathrm{Ni}-3 \mathrm{wt} \% \mathrm{Al}$ were levitation melted and sprayed with the halide, a solid crust was formed. However, it differed both in appearance and in thermal properties from the crusts described above. It could be solidified in situ $t h$ a helium flow rate of 20 litres per minute while the crusts on UDIMET 720 were not solidified at helium flows of 30 litres per minute due to poor thermal conductivity of the scale 
s
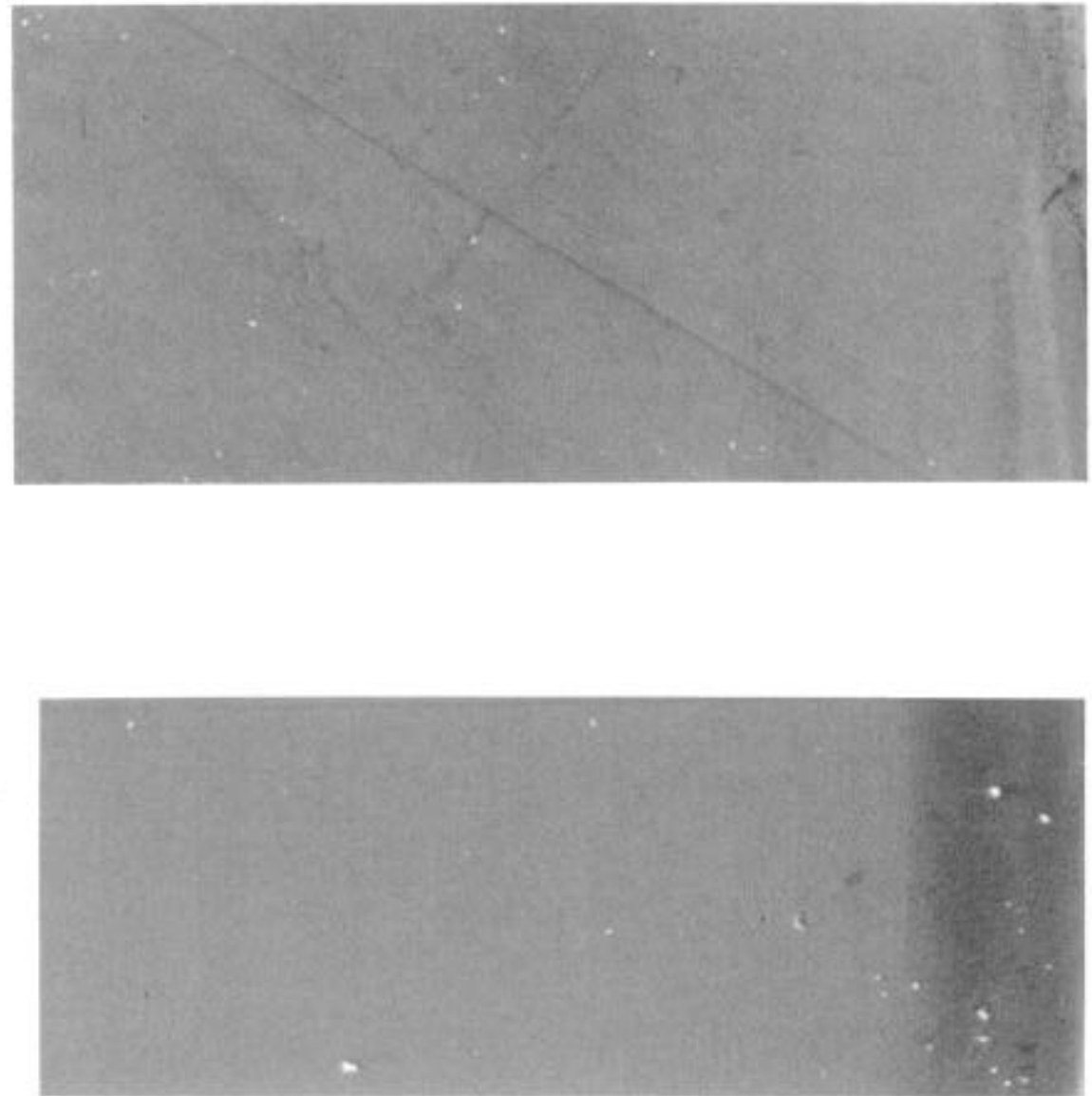

c

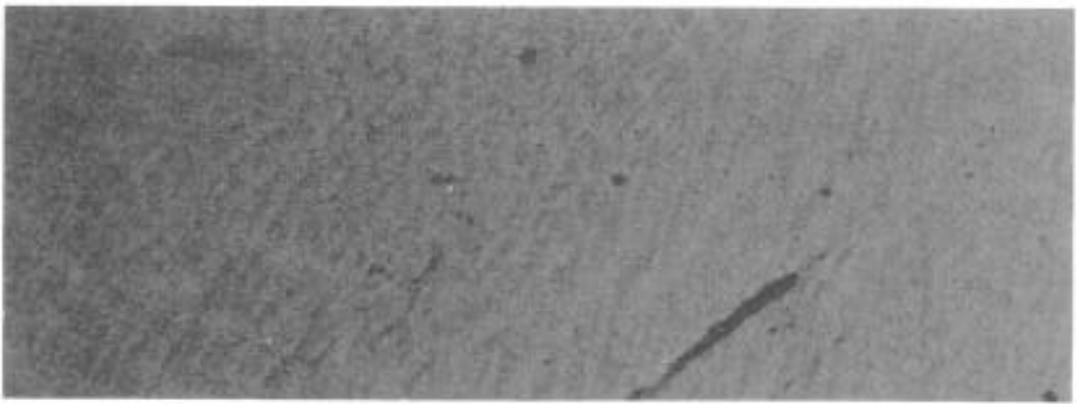

Figure 4 Sections of UDIMET 720:

(a) as-supplied, (b) as supplied and levitated and (c) as supplied and levitated with $\mathrm{KCl}$ additions.

Scale:

$100 \mu \mathrm{m}$ 
It appears that the addition of the halides, by changing the surface characteristics of the molten sample, result both in the entrapment of inclusions impinging on the surface and oxidation of some of the more reactive constituents of the alloy such as aluminium. Due to its high boiling point the compound $\mathrm{CaF}_{2}$ is considered as a particularly appropriate addition to enhance inclusion removal from the molten alloy.

Samples of the alloy were doped with 15 to $20 \mathrm{ppm}$ sulphur as a surface active element. Visual observation and a study by SEM showed no significant change in the wetting characteristics of any of the inclusions. However, this does not prove that sulphur has no effect on the surface properties of the alloy. Quantitative evaluation would be required to determine the effect of sulphur on the surface characteristics of the inclusions. As an indication of the effect of sulphur on the inclusions, as mentioned above most of the wetting inclusions contained some sulphur.

\section{CONCLUSIONS}

1. During levitation melting of both pure nickel and UDIMET 720 , powder additions of alumina and spinel concentrated on the surface; TiN dissolved in the melt.

2. In melting as-supplied UDIMET 720 inclusions of alumina, titanium aluminate and complex oxides of aluminium, silicon, calcium, magnesium and titanium were retained at the drop surface; small inclusions, predominantly variants of aluminium silicate with associated sulphur, were observed within the drops.

3. The addition of alkali metal halides enhances the efficiency of collection of inclusions at the surface of the levitated drop and dramatically reduces the inclusion content within the drop. A thin solid crust forms around the molten drop and it is proposed that the crust is a composite of inclusions retained at the surface and bonded by the oxidation products of the reactive metals in the alloy.

\section{ACKNOWLEDGEMENTS}

The authors thank EPSRC for support of this work (Grant Number), Rolls Royce ple for provision of the UDIMET 720 alloy, INCO Alloys Ltd for technical support and Professor K.C.Mills for advice during the execution of the work.

\section{REFERENCES}

1- J. ADAMS et al, Proceedings of 1st International Conference on Processing Materials for Properties, Honolulu - USA, 7-10th Nov 1993.

2- R. HASEGAVA, Met. Tech. (JPN), 61, (11), (1991), 12 15.

3- L. MAKECHAL et al, Proceedings of Conference Light Metals 1993, Denver - USA, 21-25th Feb 1993

4- M.J. KOCZAK et al, Proceedings of Conference Advanced Materials for Future Industries, Chibo Japan, 11-14th Dec 1991.

5- H.R. LOWRY et al, Proceedings of Conference Metallurgical Processes for the Year 2000 and Beyond, Las Vegas - USA, 27th Feb - 3rd Mar 1989.

6- $\quad$ R.I. ASFAHANI et al, J. Met., 37, (4), (1985), 22-26.

7- $\quad$ R. MORALES et al, Proceedings of 2nd Japan-Sweden Joint Symposium on Ferrous Metallurgy, Tokyo, Japan, 12th Dec 1978.

8- A. MITCHELL, Progress in understanding clean metal production, Dept. of Metals and Materials Engineering, University of British Columbia, Vancouver - Canada.

9- S. CHAKRAVORTY et al, Characterisation of inclusions in a nickel based superalloy by $E B B M$, Division of Materials Applications, National Physical Laboratory, Teddington, Middlesex, UK.

10- J.D. ELLIS, Quality Assurance by Electron Beam Button Melting, Ph.D. Thesis, University of London 1992 (Dept. of Materials, Imperial College, London - UK.)

11- L. BARNARD et al, Iron \& Steel Making, 20, (5), (1993), p. 334. 